\title{
Five-year Survey of the Treatment of Varicose Ulcers
}

\author{
MARY E. F. HENRY, W. G. FEGAN, J. M. PEGUM
}

British Medical fournal, 1971, 2, 493-494

\section{Summary}

Eighty-two consecutive women with varicose ulcers werc treated by compression sclerotherapy; $73\left(89^{\circ}{ }_{0}\right)$ of them were reviewed 46 to 69 months after treatment. The cure rate at follow-up for the whole group was $82^{\circ}{ }_{0}$. In obese patients the cure rate was $76^{\circ}$, while in non-obese patients it was $89^{\circ}$. These results compare favourably with those of surgery.

\section{Introduction}

One of the reasons for controversy over the treatment of varicose veins is the difficulty of comparing different methods, due to disagreement as to what constitutes a satisfactory result. However, one feature of a satisfactory treatment, about which there can be little disagreement, is the cure and prevention of recurrence of a varicose ulcer. A survey is reported here of patients with varicose ulcers who had been treated by injection compression sclerotherapy four to five years previously.

\section{Patients}

Eighty-two consecutive women with varicose ulcers who had attended the first visit varicose vein clinic at Sir Patrick Dun's Hospital were reviewed. All had been treated as outpatients by compression sclerotherapy (Fegan, 1967). This involves the injection of a sclerosant at the sites of junction of the incompetent perforating veins with the superficial veins. Continuous compression is then applied at the injection sites, with rubber pads, crepe bandages, and elastic stockings, and maintained for at least six weeks. Patients are instructed to walk at least 3 miles $(4.8 \mathrm{~km})$ each day and to avoid standing. Obese patients are advised to lose weight. One of us (J.M.P.) treated all the patients involved.

The ulcers of alternate patients were dressed with sterile lint or with polynoxylin paste on similar sterile lint. The dressing produced no significant difference in the rates of healing (Pegum and Fegan, 1968). The size of the ulcers varied from 567 to $8 \mathrm{~mm}^{2}$, with a mean of $113 \mathrm{~mm}^{2}$.

\section{Results}

The patients were assessed 46 to 69 months after starting treatment. Of the 82 patients $73\left(89^{\circ}\right)$ were reviewed. One of the remainder had died and the other eight had changed their addresses and could not be traced. There was a clinical impression that obese patients had ulcers which were more difficult to treat and were more likely to recur. This was confirmed by the average weights of the two groups as the

Sir Patrick Dun's Hospital, Dublin 2

MARY E. F. HENRY, M.D., Research Assistant

Trinity College, Dublin

W. G. FEGAN, M.CH., F.R.c.S.I., Professor of Surgery

Adelaide Hospital, Dublin 8

J. M. PEGUM, M.D., F.R.C.S., Orthopaedic Registrar patients whose ulcers had recurred weighed on average $18 \frac{1}{2} \mathrm{lb}$ $(8.4 \mathrm{~kg})$ more than those in whom no recurrence had occurred.

The patients were classified as regards obesity by comparing their weights, heights, and ages with a Standard Insurance Institute Table. Those whose weights were more than $10^{\circ}$ ' over their "correct" weights were classified as obese. With this criterion, 39 patients were found to be obese and 34 non-obese. The cure rates of the obese patients was $76^{\circ}{ }_{0}$, while for the non-obese it was $89^{\circ}, \mathrm{o}$. The cure rate at review of the whole group followed up was $82 \%$.

Several patients had suffered from ulcers for 20 to 30 years, they had healed occasionally. The longest continually unhealed ulcer was 168 months and the shortest one month.

\section{Discussion}

Anning (1956) used compression bandaging in treating 100 patients with varicose ulcers. His cure rate at two and a half to seven years after treatment was $41^{\circ}{ }_{0}$. Anderson and McDonald (1963) treated ulcers by excision of skin and subcutaneous tissue in the ulcer area and grafting of the ulcer bed. In a series of 40 patients followed up for from one to nine years they reported a cure rate of $95^{\circ}{ }_{\circ}$. Lofgren, Lauvstad, and Bonnemaison (1965) reviewed 112 patients 3 to 12 years after treatment by grafting, with or without stripping of the involved incompetent veins. The curc rate was $70 \%$. Haegar (1966) treated the ulcers of 49 patients with colloidal silver spray (if infected) followed by aluminium foil compresses, foam rubber pads, and elastic bandages. Once the ulcer was healed, ligation of the ankle perforating veins, together with either popliteal vein resection or transposition of the gracilis muscle, was performed. At three to six years after treatment the cure rate was $83^{\prime \prime} \circ$. Arnoldi (1967) reviewed 226 patients three to six years after treatment. This involved preliminary compression bandaging followed by stripping of the main saphenous veins and their varicosc tributaries, with ligation of incompetent perforating veins. The cure rate was $92 \%$.

Almost all varicose ulcers can be induced to heal by simple means, of which firm compression is the most important. It follows that the efficacy of any particular form of treatment must depend largely on the prevention of recurrence. This must bc determined by follow-up for a reasonably long period.

The overall cure rate of $82 \%$ at four to five years in the patients reviewed here is not as good as that reported in some of the series mentioned above. However, the figures may not be directly comparable, as the higher cure rates were achieved by surgical treatment. This implies a degree of selection, as patients who were unfit for surgery would have been excluded. Obesc patients are more likely to be unfit for surgery than those of normal weight, and it is shown here that they have a higher recurrence rate. Fitness or otherwise for operation was not determined in the patients reported here, but it would seem that the results in the non-obese patients are more comparable with patients treated surgically than are the results for the whole group.

The cure rate of $89 \%$ in non-obese patients at four to five years is in accordance with the view that compression sclerotherapy achieves results as good as those of surgery.

One of us (M.E.F.H.) was in receipt of a full-time fellowship from the Medical Research Council of Ireland.

Requests for reprints should be sent to Professor W. G. Fegan, Research Department, Sir Patrick Dun's Hospital, Dublin 2. 


\title{
Response of Aspirin-allergic Patients to Challenge by Some Analgesics in Common Use
}

\author{
A. P. SMITH
}

British Medical fournal, 1971, 2, 494-490

\section{Summary}

Challenge tests with some analgesics in common use were performed in five aspirin-sensitive asthmatics. Marked falls in FEV 1 were observed after ingestion of paracetamol, indomethacin, mefenamic acid, and dextropropoxyphene in some subjects. The mechanisms of analgesic-induced asthma are discussed: it is believed to be a non-immunological process of great practical importance when prescribing analgesics to asthmatics.

\section{Introduction}

Symptoms of asthma, chronic rhinitis, urticaria, and angioncurotic oedema may occur in patients who arc allergic to aspirin (Van Leeuwen, 1924; Bruce Pearson, 1963; Samter and Becrs, 1968). These symptoms rarely occur in the same patient, and more usually asthma, rhinitis, and urticaria are seen scparately. Classically, the syndrome first presents in the third or fourth decade of life with watery nasal discharge, and later with nasal polypi. After a variable interval from weeks to years, bronchial asthma is first noticed, often being precipitated by nasal polypectomy or by aspirin ingestion. Thereafter the patient experiences persistent wheezing with severe, even life-thrcatening, attacks of asthma after taking aspirin. Avoiding aspirin, however, does not abolish the asthma, which is usually well controlled by small regular doses of corticosteroids.

In addition to aspirin, other drugs or chemicals may precipitate attacks of asthma in patients who suffer from this condition. These include alcohol, indomethacin, amidopyrine, and tartrazine (Samter and Beers, 1968), the latter being a ycllow colouring material commonly found in soft drinks, canned vegetables, and many other foodstuffs.

This paper presents the results of air-flow measurements on five aspirin-sensitive patients challenged by some other commonly used analgesics. Samter and Beers (1968) challenged aspirin-sensitive patients with a number of salicylic acid esters, thioaspirin, and paracetamol, but recorded no untoward effects. They did not, however, include any specific measurement of bronchial constriction.

\section{Patients and Method}

Dctails of the case historics of the firc patients are presented in Table I. Two were admitted specifically for the tests, two were admitted with status asthmaticus and subsequently investigated, and in one all tests were performed as an outpatient. The nature of the tests was explained to the patients. One (Case 2)

TABLE 1-Details from the Case Histories of the P'atients Investigated

\begin{tabular}{|c|c|c|c|c|c|}
\hline & Case 1 & Case 2 & Case 3 & Case 4 & Case 5 \\
\hline 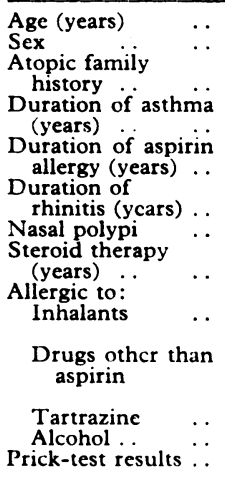 & $\begin{array}{c}47 \\
1 . \\
0 \\
10 \\
10 \\
15 \\
\text { Present } \\
1 \\
0 \\
\text { Para- } \\
\text { cetamol } \\
\text { Yes } \\
\text { Yes } \\
\text { Eggs. } \\
\text { Milk }\end{array}$ & $\begin{array}{c}48 \\
\text { F. } \\
\text { Present } \\
4 \\
4 \\
8 \\
\text { Present } \\
1 \\
0 \\
\\
\text { Paracetamol. } \\
\text { Indomethacin. } \\
\text { Penicillin } \\
\text { Yes } \\
\text { Yes } \\
0\end{array}$ & \begin{tabular}{|c|}
34 \\
M. \\
0 \\
3 \\
2 \\
2 \\
0 \\
0 \\
Pollen. \\
Ilouscdust \\
0 \\
\\
0 \\
0 \\
Grass pollen. \\
House mitcs
\end{tabular} & 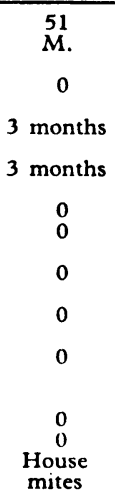 & $\begin{array}{c}6 \\
\text { Present } \\
0 \\
0 \\
0 \\
\\
0 \\
0 \\
\text { Tree } \\
\text { pollcn }\end{array}$ \\
\hline
\end{tabular}

had a history of recurrent backache treated with indomethacin associated with severe asthmatic symptoms, and ultimately status asthmaticus. Another (Case 1) had noticed exacerbations of her wheeze and chronic rhinitis after the use of paracetamol. All the patients had a clear history of asthma attacks after taking aspirin.

The patients were challenged by the following drugs in no set order: paracetamol $500 \mathrm{mg}$, mefenamic acid $250 \mathrm{mg}$, indomethacin $25 \mathrm{mg}$, dextropropoxyphene $65 \mathrm{mg}$, phenylbutazone $100 \mathrm{mg}$, and inert white lactose tablets. Aspirin itself was not used because a cautious pilot study in one patient had shown it might be dangerous. The tests were performed under the same circumstances in each patient, and in all cases smoking and the consumption of soft drinks, tea, or coffee was forbidden, and so was the use of a bronchodilator drug for 12 hours before the test. The forced expiratory volume in onc sccond $\left(\mathrm{FEV}_{1}\right)$ was measured every 30 minutes on a dry bellows type spirometer (Vitalograph), the maximum of three consecutive readings being recorded. Any uncomfortable wheezing was relieved by inhaling $0.5^{\circ}{ }_{0}$ isoprenaline from a Wright's nebulizer flowing at 8 litres/min and the test was terminated. 